\title{
IMPETIGO CONTAGIOSA
}

\section{THE ASSOCIATION OF CERTAIN TYPES OF STAPHYLOCOCCUS AUREUS AND OF STREPTOCOCCUS PYOGENES WITH SUPERFICIAL \\ SKIN INFECTIONS}

BY M. T. PARKER, Public Health Laboratory, Manchester

\author{
A. J. H. TOMLINSON,
}

Bacteriological Laboratory, County Hall, London

AND R. E. O. WILLIAMS,

Streptococcus and Staphylococcus Reference Laboratory, Central Public Health Laboratory, Colindale

Impetigo contagiosa may be defined as an acute, superficial infection of the skin characterized by exudation and crusting. In this country it is at present mainly seen in children, although it has been an important cause of minor illness among troops in wartime. It appears to have become much less common in the last 10 years, though a recent increase in incidence has been reported (Sneddon, 1953). In the 90 years since the original clinical description of Fox (1864) there appear to have been repeated fluctuations in the prevalence of the disease, and also differences in frequency, severity and predominant clinical type in different parts of the world. It is not surprising, therefore, that there have been great discrepancies between the bacteriological findings of various workers, and that the controversy between the supporters of the staphylococcal and the streptococcal theories of the aetiology of the disease has continued for almost 60 years. Most dermatologists now recognize the existence of at least two clinical types of impetigo, associated respectively with haemolytic streptococci and with Staphylococcus aureus, though it is not always possible to make such a clinical distinction in the individual case (Epstein, 1940).

The investigation reported here falls into two parts, the first of which was carried out in association with Dr L. C. Martin in Cambridge in the years 1941-2 and was concerned with impetigo in young adult service men. The second was occasioned by an increased prevalence of impetigo in the City of Salford in 1953 (Burn, 1954), particularly during the last few months of the year. There was an unusually high proportion of severe cases, many of which were of the bullous type.

The Cambridge investigation showed that a large proportion of Staph. aureus strains from impetigo cases (and a much smaller proportion from other sources) had the ability to inhibit corynebacteria. The Manchester investigation showed that most of the impetigo staphylococci belonged to a single unusual phage type, members of which were usually able to inhibit corynebacteria and were penicillinresistant, and that the haemolytic streptococci were largely confined to two particular serological types. 


\section{METHODS}

In the Cambridge investigation, swabs from a single lesion of each patient were plated without delay on to blood-agar plates with and without $1: 500,000$ crystal violet. Coagulase tests on the staphylococci were carried out in tubes using $1: 5$ dilution of fresh human plasma. All coagulase-positive staphylococci were considered to be Staph. aureus. Haemolytic streptococci were grouped by Fuller's (1938) method.

In the Manchester investigation, material from the lesions of impetigo cases was collected on serum-impregnated swabs (Rubbo \& Benjamin, 1951) which, in most cases, were delivered to the Salford Public Health Laboratory on the same day. The swabs were inoculated on to $7 \%$ layered horse-blood agar plates, and on to similar plates in which 1:500,000 crystal violet had been incorporated. Both plates were incubated at $37^{\circ} \mathrm{C}$. aerobically and examinated on the following morning. The ordinary blood-agar plates were re-examined after a further 1 day at room temperature. Nasal swabs of school-children were inoculated directly on to blood-agar plates at the time of collection.

Colonies resembling haemolytic streptococci were subcultured to fresh bloodagar plates to ensure purity and grouped by Fuller's method. Members of Lancefield's Group A (Streptococcus pyogenes) were stored in Robertson's cooked meat medium and sent in batches to the Streptococcus Reference Laboratory for serological typing. Type identification was carried out by both the slide agglutination (Griffith, 1934) and the precipitin (Swift, Wilson \& Lancefield, 1943) methods. The methods and typing sera used were those recently described (Report, 1954).

Colonies thought to be Staph. aureus were tested for coagulase production by the slide test (Cadness-Graves, Williams, Harper \& Miles, 1943) and those giving a negative result also by the tube test (Fisk, 1940). Cultures of all coagulasepositive staphylococci were stored in nutrient agar stabs in the dark at room temperature and were phage-typed in batches by the method of Williams \& Rippon (1952), using the phages both at their routine test dilution (dilute phage) and also at 1000 times the routine test dilution $(1000 \times$ R.T.D. $)$. The phages comprised the 'basic set' of Williams, Rippon \& Dowsett (1953), omitting phage 44, but with the addition of phage 71 .

All strains of Staph. aureus were tested for penicillin sensitivity. Parallel streaks were made on nutrient agar plates with a straight wire charged from a fresh growth on a solid medium. Four test strains and the Oxford staphylococcus were inoculated on each $10 \mathrm{~cm}$. plate. A filter-paper strip $8 \mathrm{~mm}$. wide, which had been previously soaked in a penicillin solution ( 75 units $/ \mathrm{ml}$.) and subsequently drained, was placed on each plate at right angles to the streaks. Resistant strains grew up to the strip or to within $1 \mathrm{~mm}$. of it. Strains were considered to be sensitive if the zone of inhibition was half as wide as that of the Oxford staphylococcus.

\section{Inhibition of corynebacteria}

Cambridge investigation. After preliminary experiments with a number of strains, a diphtheroid bacillus, which was highly susceptible to inhibition by Staph. aureus, was chosen as the indicator organism. Growth from an $18 \mathrm{hr}$. culture on 
a slope of Loeffler's medium was emulsified in $0.5 \mathrm{ml}$. nutrient broth, and 3 drops were spread evenly over a well-dried blood-agar plate to give confluent growth. Immediately afterwards strains of Staph. aureus were spotted on to the plates with a wire and the plates were incubated for $48 \mathrm{hr}$. at $37^{\circ} \mathrm{C}$. With an inhibitory strain of Staph. aureus a zone of inhibition of the diphtheroid, with a clear, sharp margin, extended for $2-3 \mathrm{~mm}$. around the spot of staphylococcal growth. The diphtheroid grew right up to the margin of the spots of non-inhibitory staphylococci.

Manchester investigation. A non-virulent strain of Corynebacterium diphtheriae mitis (no. 51 in the collection of the Manchester Public Health Laboratory) was selected for routine use. The most consistent results were obtained if a very heavy inoculum was used giving an even sheet of growth in which individual colonies could not be seen. Therefore, a small loopful of growth from a $24 \mathrm{hr}$. blood-agar culture was spread evenly over the whole surface of a freshly poured and dried blood-agar plate. Almost immediately afterwards, $3 \mathrm{~mm}$. loopfuls of overnight broth cultures of staphylococci were spotted on to the plate (seven to each $10 \mathrm{~cm}$. plate). Readings were made after overnight incubation at $37^{\circ} \mathrm{C}$. Plates were opened, laid growth upward on a dark bench surface and examined obliquely under a strong light and the inhibition assessed as in the Cambridge investigation.

\section{RESULTS}

The Cambridge investigation (1941)

The bacteriological examination of cases of impetigo admitted to hospital in Cambridge suggested that Staph. aureus was the most important pathogen present in the lesions. Thus, of 298 patients Staph. aureus was present alone in 158, Staph. aureus and haemolytic streptococci were found together in 134, and two yielded haemolytic streptococci only. Neither organism was recovered from the lesions of four patients. Of 126 strains of haemolytic streptococci, 109 belonged to Lancefield's Group A (Str. pyogenes). Dr N. Crowley typed many of the strains by agglutination, but difficulties were encountered due to the large number of crossreactions. The results will be mentioned briefly on p. 470. It was noticed that the proportion of lesions from which haemolytic streptococci were isolated increased with the duration of the lesion, but that the organism was isolated from a proportion of the earliest lesions. Investigations by other workers (Bigger \& Hodgson, 1943; Sheehan \& Fergusson, 1943) gave similar results.

An attempt was made to find the source of the staphylococci in impetigo lesions, but the problem was rendered difficult by the widespread presence of Staph. aureus in the nose and on the skin of normal persons. Phage-typing had not yet come into use, and no sera for typing by agglutination were available in Cambridge. A search was therefore made for some biological test which would distinguish the impetigo strains from the others.

The inhibition of $C$. diphtheriae by some strains of staphylococci has been known for many years; the earlier literature was reviewed by Florey, Chain, Heatley, Jennings, Sanders, Abraham \& Florey (1949). Dujardin-Beaumetz (1932) showed that staphylococci possessing this property were more or less active against all 
corynebacteria, as well as various other Gram-positive bacilli, and that the effect was seen only on solid media. Similar observations were made by Duliscouët (1935, 1939, 1945), Jennings \& Sharp (1947) and Váczi \& Mihályfi (1954), but none of these workers noted that inhibitory strains were associated with any particular type of lesion.

It was observed that a large proportion of the strains isolated from impetigo lesions had the ability to inhibit the growth of $C$. diphtheriae and other corynebacteria on solid media. Strains from other sources less commonly had this ability.

The inhibition of mitis and gravis strains of $C$. diphtheriae was usually much greater than that of intermedius strains or of C.xerosis. Inhibition could be demonstrated on serum agar and on nutrient agar, but was best seen on blood agar. It took place both aerobically and anaerobically, and also on media containing staphylococcal antitoxin or an agglutinating serum prepared against an inhibitory strain of Staph. aureus, The power to inhibit was not retained indefinitely in culture. Non-inhibiting variants, both white and golden, could be obtained by plating out old cultures.

Proportion of inhibitory strains among Staphylococcus aureus cultures from various sources. Collections of Staph. aureus cultures from (1) impetigo lesions, (2) other skin infections, (3) superficial septic lesions, such as infected wounds, burns, conjunctivitis and otitis, (4) deep septic lesions, including boils and abscesses, and (5) nose and throat swabs of healthy persons, and persons with sore throat or miscellaneous fevers, were examined for inhibitory power (Table 1). Nearly half

Table 1. Proportion of strains of Staphylococcus aureus from different sources with the ability to inhibit the growth of a corynebacterium (Cambridge, 1941).

$$
\mathrm{DI}+=\text { inhibitory } ; \mathrm{DI}-=\text { non-inhibitory }
$$

\begin{tabular}{lccc}
\multicolumn{1}{c}{ Source } & $\mathrm{DI}+$ & $\mathrm{DI}-$ & $\% \mathrm{DI}+$ \\
Impetigo & 88 & $\mathbf{9 9}$ & $\mathbf{4 7}$ \\
Other skin lesions & 10 & $\mathbf{4 4}$ & $\mathbf{1 9}$ \\
Nose and throat & 18 & 157 & 10 \\
Superficial sepsis & 4 & 52 & 7 \\
Deep sepsis & 0 & 61 & 0
\end{tabular}

$(47 \%)$ of the strains from impetigo lesions inhibited the diphtheroid organism $(\mathrm{DI}+)$. A smaller proportion (19\%) of strains from other skin infections and only $7 \%$ from other superficial lesions were DI + . No positive strains were found among sixty-one from deep lesions. However, $10 \%$ of cultures from the nose and throat swabs of patients not suffering from skin disease or superficial sepsis were $\mathrm{DI}+$.

\section{The Manchester investigation}

Isolation of Staphylococcus aureus and of haemolytic streptococci from swabs of impetigo lesions. From October to December 1953, swabs taken from the lesions of 145 patients with impetigo on their first attendance at Salford school clinics were examined. A small number from the neighbouring Borough of Eccles, where the disease also appeared to be unduly common, from the City of Manchester, where 


\section{M. T. Parker, A. J. H. Tomlinson and R. E. O. Williams}

no increase had been noted, and from cases in the early part of 1954, brought the total to 190 .

Table 2 summarizes the results of the culture of swabs from a single lesion of each case. Staph. aureus was isolated from $158(83 \%)$, and in $84(44 \%)$ was the only potential pathogen found. Of the 158 strains $74 \%$ were penicillin-resistant. Str. pyogenes was isolated from $90(47 \%)$, and was present alone in $25(13 \%)$. Of the 10 strains of haemolytic streptococci of groups $\mathrm{C}$ and $\mathrm{G}$, all except one were present in mixed culture with Staph. aureus.

Table 2. Presence of Staphylococcus aureus and of haemolytic streptococci in lesion swabs of 190 cases of impetigo in south-east Lancashire. One swab from each patient on first attendance at a clinic (1953 and early 1954)

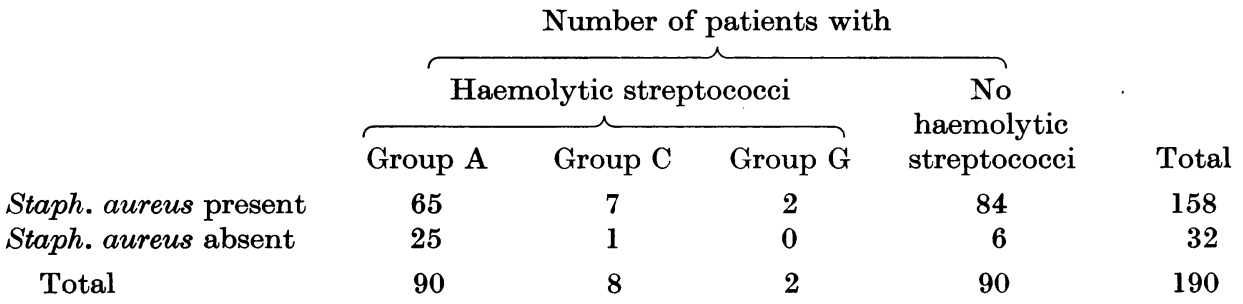

Phage-typing of Staphylococcus aureus strains from impetigo and from other infections. The first 40 strains of Staph. aureus from Salford impetigo cases were typed with the 19 phages in routine use in the Manchester Public Health Laboratory (see Table 3). Thirty-three of these 40 strains failed to show any lysis by the phages when tested with dilute phage, but gave faint reactions with one or more of the group II phages, $3 \mathrm{~B}, 3 \mathrm{C}$ and 55 when tested at $1000 \times$ RTD. As such

Table 3. Phages used in the typing of Staphylococcus aureus and the groups of staphylococci defined by the pattern of lysis by these phages Group

Reaction with phages

I

II

III

Unclassifiable

Not typable
$29,52,52 \mathrm{~A}, 79$

$3 \mathrm{~A}, 3 \mathrm{~B}, 3 \mathrm{C}, 55,(71)^{*}$

$6,7,42 \mathrm{E}, 47,53,54,70,73,75,77,42 \mathrm{D} \dagger$

Reactions with phages of more than one group

No strong reaction with any phage ( $<50$ plaques)

* Not in 'basic' typing set until after this work had been carried out.

$\dagger$ Now provisionally allocated to a separate 'Group IV'.

findings are not common among strains from other sources, a small selection of cultures was tested with other, less commonly used, group II phages. All gave a clear-cut strong reaction with phage 71 when applied dilute. Strains lysed by phage 71 but not by other group II phages at the RTD had not been commonly encountered previously. Therefore, phage 71 was included in all subsequent tests, and it was found that the majority of strains from impetigo lesions in Salford were lysed by it, suggesting the existence of a specific 'type 71' staphylococcus. 
Since staphylococci are usually lysed by several typing phages, and related strains may show small differences in their 'reaction patterns' (Williams \& Rippon, 1952), it was important to investigate the degree of variability in the pattern of lysis shown by 'type 71 ' strains isolated from impetigo cases; this necessitated the setting up of strict criteria for the inclusion of strains in the 'type'. To be included, a strain had to be lysed by phage 71 (usually but not always by dilute phage), and by no other dilute phage. Small variations of pattern within these limits were observed, and in order to assess their importance they were classified as follows.

(1) 'normal 71': lysis by dilute phage 71 , but by no other dilute phage: lysis by one or more other group II phages at $1000 \times$ RTD.

(2) 'pure 71 ': lysis by dilute phage 71 , but no lysis by any other phage, even at $1000 \times$ RTD.

(3) 'weak 71 ': lysis by phage 71 , and usually also by other group II phages, at $1000 \times$ RTD, but no lysis by any dilute phage.

Table 4 summarises the results of phage-typing 158 impetigo strains of Staph. aureus from Salford and neighbouring towns. Three-quarters of them (119/158) belonged to 'type 71 ', and of these 104 conformed strictly to the criteria for 'normal 71 '. The remainder of the strains were fairly evenly distributed among the other main phage groups, and many different patterns of lysis were represented.

Table 4. Phage-typing of 158 strains of Staphylococcus aureus from impetigo lesions (south-east Lancashire)

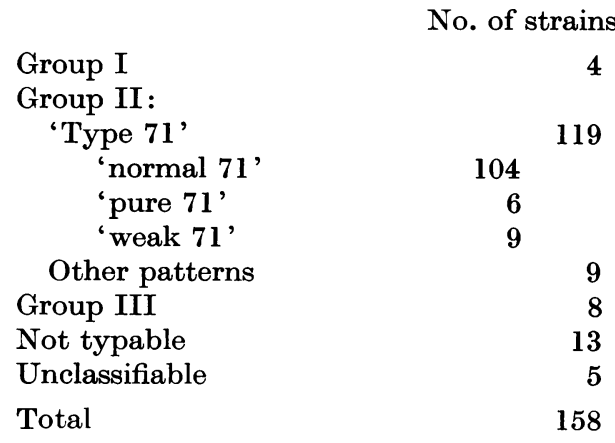

The finding that the majority of Staph. aureus from impetigo lesions in one geographical area were of one 'type' suggested that we might have encountered a local epidemic due to a strain of unusual virulence or infectivity. However, the distribution of cases in Salford showed no concentration in one district or association with one particular school, and 'type 71' Staph. aureus was isolated not only from cases in the neighbouring town of Eccles, but also from sporadic cases in districts of Manchester where no increased prevalence had been noted.

It seemed possible that the existence of a 'carrier-epidemic' of 'type 71' Staph. aureus in the noses of the population might explain our findings, and we decided to investigate the nasal flora of Salford school-children. Nose swabs were collected from 100 children aged 8-11 years in each of two primary schools. At one, in the 


\section{M. T. Parker, A. J. H. Tomitnson and R. E. O. Williams}

crowded centre of the City, several cases of impetigo had occurred recently, but at the other, on the periphery, no cases had been seen. A single strain of Staph. aureus from each positive swab was isolated and phage-typed. Only 3 of 92 strains belonged to 'type 71 ', but these were from the school in which several cases had occurred.

In order to find out if the prevalence of 'type 71 ' in south-east Lancashire was a local phenomenon and, if so, to define the extent of its geographical distribution, 117 strains from impetigo lesions in other parts of the country were typed at the Manchester Public Health Laboratory (Table 5). The largest series consisted of

Table 5. Phage types of Staphylococcus aureus strains from impetigo lesions in various parts of England

\begin{tabular}{|c|c|c|c|c|c|c|}
\hline \multirow[b]{2}{*}{ Group } & \multicolumn{3}{|c|}{ Typed at Manchester P.H.L. } & \multirow{2}{*}{$\begin{array}{c}\text { Typed at } \\
\text { Staphylococcus } \\
\text { Reference Lab. } \\
\text { D }\end{array}$} & \multicolumn{2}{|c|}{ Total } \\
\hline & $\mathbf{A}$ & B & $\mathrm{C}$ & & No. & $\%$ \\
\hline I & 4 & 8 & 1 & 7 & 20 & 6 \\
\hline \multicolumn{7}{|l|}{ II: } \\
\hline 'type 71' & 119 & 31 & 19 & 26 & 195 & 61 \\
\hline Other patterns & 9 & 21 & 2 & 8 & 40 & 12 \\
\hline III & 8 & 15 & 5 & 4 & 32 & 10 \\
\hline Not typable & 13 & 13 & 2 & 2 & 30 & 9 \\
\hline Unclassifiable & $\mathbf{5}$ & 0 & 0 & 0 & $\mathbf{5}$ & 2 \\
\hline Total & 158 & 88 & 29 & 47 & 322 & 100 \\
\hline
\end{tabular}
A, strains from south-east Lancashire.
$B$, strains from Leicester.
C, strains from Birmingham, Lincoln, Luton, Stafford, Wakefield.
D, strains from Bedford, Bournemouth, Brighton, Hereford, Luton, Middlesbrough, Ports- mouth, Sheffield, Southampton, Winchester.

88 strains from the City of Leicester and Leicestershire and, the remaining 29 were from five other districts. A further 47 strains isolated in various Public Health Laboratories in widely separated parts of the country were typed at Colindale. 'Type 71' strains were commonly encountered in all districts from which cultures were received, though rather less frequently in the Leicester series than in the others.

Since a single 'type' of staphylococcus was predominant in impetigo lesions, it was of some interest to investigate its frequency in other staphylococcal infections occurring in the same area. A collection of 212 strains from various sources was examined: 114 were from infections of the newborn and the rest were from deep and superficial lesions in older persons. They were obtained from various hospitals, and from material submitted by general practitioners, in and around Manchester. They were widely distributed epidemiologically; the strains from infections of the newborn included representatives of at least 34 different incidents of infection.

All except one of the 114 cultures from infections of the newborn were from hospital patients. Table 6 summarizes the results of phage-typing in relation to the 
type of lesion. Only 14 strains of 'type 71 ' were found, 11 from bullous or pustular skin infections (pemphigus neonatorum), and the remaining 3 from other types of lesion ( 1 whitlow, 1 axillary abscess, 1 conjunctivitis). 'Type 71 ' infections were identified in all three hospitals from which more than a few strains were examined. It is interesting to note that they were always sporadic in occurrence and formed only a small part of the infections taking place.

Sixty-nine of the 98 strains from patients other than newborn infants were from hospital in-patients and 29 from patients outside hospital. Only 9 strains of 'type 71 ' were found. From Table 6, which also shows the results of phage-typing in relation to the situations of the lesions, it will be seen that 'type 71' was entirely confined to cases of superficial sepsis. None of the 50 strains from boils, abscesses, pleural effusions, or blood cultures was of this type. The origin of the strains of 'type 71 ' from superficial lesions was: aural discharge 5 (of 28 specimens), nasal discharge 1, sinus 1 , septic burn 1, sore on leg 1 .

Inhibition of corynebacteria by Staphylococcus aureus. A collection of 623 strains of Staph. aureus was tested for ability to inhibit the growth of $C$. diphtheriae mitis and also for sensitivity to penicillin (see p. 467). These strains included 275 from impetigo lesions (Table 5, columns A, B and C), 212 from other septic infections (Table 6), 92 from the noses of Salford schoolchildren, and a miscellaneous group from repeat swabs of impetigo cases and from nasal swabs of impetigo cases and contacts.

Table 6. Phage-typing of strains of Staphylococcus aureus from various infections

Newborn infants

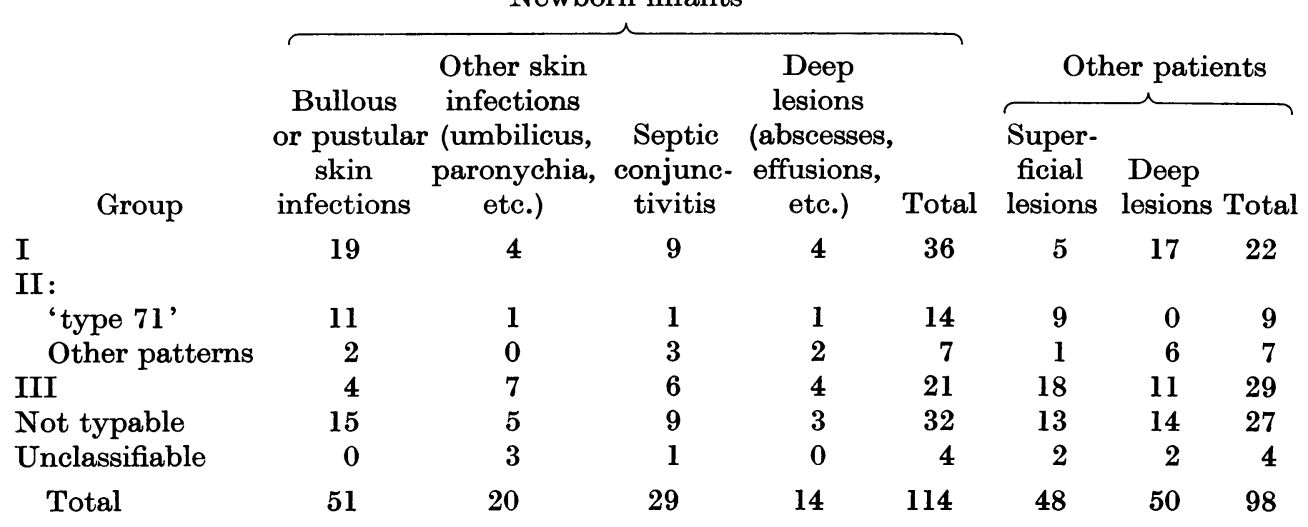

The results of inhibition tests were analysed in relation both to the source of the strains tested and to the phage-typing result. The figures in Table 7 did much to explain the differences in frequency of DI + strains in various types of lesion. Nearly $90 \%$ of 'type 71 ' strains were DI +, whether derived from impetigo lesions or from other sources. Strains belonging to groups I and III, and group II strains other than 'type 71 ', included few with the power to inhibit (3-6\%), but considerably more of the non-typable $(16 \%)$ and unclassifiable $(18 \%)$ strains were inhibitors. 


\section{M. T. Parker, A. J. H. Tomlinson and R. E. O. Williams}

The picture was further clarified by the observation that a staphylococcus could give rise to one of two distinct types of inhibitory zone. The type invariably shown by 'type $7 \mathrm{l}$ ' strains was sharply defined and relatively narrow $(2-4 \mathrm{~mm}$.), but that shown by many other strains was wider (more than $5 \mathrm{~mm}$.) and hazy at the periphery. A record was kept of the type of zone produced by all inhibitory strains, and the results are summarized in Table 8 . The hazy zone was most often produced by non-typable and unclassifiable strains, but occasionally also by members of group I. The percentage of strains of all groups other than 'type 7l' giving rise to sharp zones was $6 \%$ or less.

Table 7. Proportion of inhibiting strains in 'type 71 ' and in the main groups of phage types of Staphylococcus aureus from impetigo lesions and from other sources

\begin{tabular}{|c|c|c|c|c|c|c|c|}
\hline \multirow{2}{*}{ Group } & \multicolumn{6}{|c|}{ Proportion DI + } & \multirow[b]{2}{*}{$\begin{array}{c}\% \mathrm{DI}+ \\
\text { (all sources) }\end{array}$} \\
\hline & Impetigo & $\begin{array}{l}\text { Nasal } \\
\text { swabs } \\
\text { (Salford) }\end{array}$ & $\begin{array}{l}\text { Infections } \\
\text { of } \\
\text { newborn }\end{array}$ & $\begin{array}{l}\text { Other } \\
\text { septic } \\
\text { lesions }\end{array}$ & $\begin{array}{l}\text { Mis- } \\
\text { cellaneous }\end{array}$ & $\begin{array}{c}\text { Total } \\
\text { (all sources) }\end{array}$ & \\
\hline I & $0 / 13$ & $4 / 17$ & $0 / 36$ & $0 / 22$ & $0 / 3$ & $4 / 91$ & 4 \\
\hline \multicolumn{8}{|l|}{ II : } \\
\hline 'type 71' & $151 / 169$ & $3 / 3$ & $13 / 14$ & $6 / 9$ & $23 / 24$ & $196 / 219$ & 89 \\
\hline Other patterns & $4 / 32$ & $0 / 28$ & $0 / 7$ & $0 / 7$ & $1 / 3$ & $5 / 77$ & 6 \\
\hline III & $2 / 28$ & $0 / 7$ & $1 / 21$ & $0 / 29$ & $0 / 3$ & $3 / 88$ & 3 \\
\hline Not typable & $8 / 28$ & $7 / 30$ & $1 / 32$ & $2 / 27$ & $3 / 9$ & $21 / 126$ & 16 \\
\hline Unclassifiable & $2 / 5$ & $1 / 7$ & $0 / 4$ & $1 / 4$ & $0 / 2$ & $4 / 22$ & 18 \\
\hline Total tested & 275 & 92 & 114 & 98 & 44 & 623 & 一 \\
\hline Total DI + & 167 & 15 & 15 & 9 & 27 & 233 & - \\
\hline$\% \mathrm{DI}+$ & 61 & 16 & 13 & 9 & 61 & 37 & \\
\hline
\end{tabular}

Table 8. The production of sharp and of hazy zones by inhibition strains belonging to 'type 71 ' and to the main groups of phage types

\begin{tabular}{|c|c|c|c|c|c|c|}
\hline \multirow[b]{2}{*}{ Group } & \multirow[b]{2}{*}{$\begin{array}{l}\text { No. } \\
\text { tested }\end{array}$} & \multirow[b]{2}{*}{$\begin{array}{l}\text { No. } \\
\text { DI+ }\end{array}$} & \multicolumn{2}{|c|}{$\begin{array}{c}\text { No. of } \\
\text { strains giving }\end{array}$} & \multicolumn{2}{|c|}{$\begin{array}{l}\text { Percentage of } \\
\text { strains giving }\end{array}$} \\
\hline & & & $\begin{array}{l}\text { Sharp } \\
\text { zone }\end{array}$ & $\begin{array}{l}\text { Hazy } \\
\text { zone }\end{array}$ & $\begin{array}{c}\text { Sharp } \\
\text { zone }\end{array}$ & $\begin{array}{l}\text { Hazy } \\
\text { zone }\end{array}$ \\
\hline I & 91 & 4 & 0 & 4 & 0 & 4 \\
\hline \multicolumn{7}{|l|}{ II: } \\
\hline 'type 71' & 219 & 196 & 196 & 0 & 89 & 0 \\
\hline Other patterns & 77 & 5 & 5 & 0 & 6 & 0 \\
\hline III & 88 & 3 & 3 & 0 & 3 & 0 \\
\hline Not typable & 126 & 21 & 5 & 16 & 4 & 12 \\
\hline Unclassifiable & 22 & 4 & 1 & 3 & 4 & 14 \\
\hline
\end{tabular}

The strains of staphylococci used by Dujardin-Beaumetz in his earliest studies of the inhibition of corynebacteria on solid media were obtained from nasal swabs. Subsequently he tested a number of others from furunculosis and osteomyelitis, and from gangrenous mastitis of sheep, and found them all devoid of inhibitory activity. The zones of inhibition on nutrient agar were about $1 \mathrm{~cm}$. in diameter. There is no record of the coagulase reactions of his cultures. Jennings \& Sharp examined 205 staphylococci, both coagulase positive and negative, for antibiotic 
activity by a cross-streaking technique on serum agar plates. The staphylococci they examined were nearly all from nose and throat swabs or from wounds, and the illustrations in their paper show that the zones of inhibition were wide. They found no correlation between inhibition and coagulase production or any other cultural character. Váczi \& Mihályfi found inhibiting strains most commonly in throat swabs.

It is probable that all these authors were describing the wide, hazy type of inhibitory effect that we found most commonly among non-typable and unclassifiable Staph. aureus strains. If so, it is not surprising that they did not observe an association of their inhibiting strains with any particular type of lesion.

Relation of penicillin sensitivity to phage type. The finding that nearly threequarters of the staphylococci from impetigo cases in south-east Lancashire were insensitive to penicillin was unexpected, since penicillin resistance had hitherto only been commonly encountered among strains from hospital infections. It was soon apparent that nearly all the resistant strains were members of 'type 71 '. In Table 9 the penicillin sensitivity of impetigo staphylococci from various parts of the country is related to the phage-typing results. Broadly speaking, the percentage of impetigo staphylococci resistant to penicillin is determined by the prevalence of 'type 71 '. In Leicester, where under half of the strains were penicillin-resistant, there was a much lower percentage (35\%) of 'type 71 ' strains than elsewhere, and a higher percentage of group II strains other than 'type 71'. There was, however, some suggestion that rather fewer of the Leicester 'type 71' strains than of the others were penicillin-resistant.

Table 9. Proportion of penicillin-resistant strains of Staphylococcus aureus

\begin{tabular}{|c|c|c|c|c|c|c|c|c|}
\hline \multirow[b]{3}{*}{ Phage group } & \multirow{2}{*}{\multicolumn{3}{|c|}{$\begin{array}{l}1 \\
\text { Impetigo lesions }\end{array}$}} & \multirow{3}{*}{$\begin{array}{c}4 \\
\text { Nasal } \\
\text { swabs } \\
\text { (Salford) }\end{array}$} & \multirow{3}{*}{$\begin{array}{c}5 \\
\text { Infections } \\
\text { of } \\
\text { newborn }\end{array}$} & \multirow{3}{*}{$\begin{array}{c}6 \\
\text { Other } \\
\text { septic } \\
\text { lesions }\end{array}$} & \multirow[t]{2}{*}{7} & \multirow[b]{3}{*}{ Total } \\
\hline & & & & & & & & \\
\hline & $\begin{array}{l}\text { S.E. } \\
\text { Lancs. }\end{array}$ & Leicester & $\begin{array}{l}5 \text { other } \\
\text { areas } \dagger\end{array}$ & & & & $\begin{array}{l}\text { Mis- } \\
\text { cellaneous }\end{array}$ & \\
\hline I & $0 / 4^{*}$ & $0 / 8$ & $0 / 1$ & $3 / 17$ & $32 / 36$ & $11 / 22$ & $0 / 3$ & $46 / 91$ \\
\hline \multicolumn{9}{|l|}{ II : } \\
\hline 'type 71 ' & $111 / 119$ & $23 / 31$ & $16 / 19$ & $3 / 3$ & $14 / 14$ & $7 / 9$ & $23 / 24$ & $197 / 219$ \\
\hline Other patterns & $1 / 9$ & $0 / 21$ & $2 / 5$ & $3 / 28$ & $2 / 7$ & $0 / 7$ & $0 / 3$ & $6 / 77$ \\
\hline III & $2 / 8$ & $7 / 15$ & $2 / 5$ & $0 / 7$ & $19 / 29$ & $18 / 29$ & $1 / 3$ & $49 / 88$ \\
\hline Not typable & $1 / 13$ & $2 / 13$ & $0 / 2$ & $1 / 30$ & $26 / 32$ & $16 / 27$ & $2 / 9$ & $48 / 126$ \\
\hline Unclassifiable & $2 / 5$ & 0 & 0 & $1 / 7$ & $3 / 4$ & $1 / 4$ & $0 / 2$ & $7 / 22$ \\
\hline Total & $117 / 158$ & $32 / 88$ & $18 / 29$ & $11 / 92$ & $96 / 114$ & $53 / 98$ & $26 / 44$ & $353 / 623$ \\
\hline
\end{tabular}

The penicillin sensitivity of 623 strains from various sources is also given in Table 9 in relation to phage type. The following conclusions can be drawn:

(1) Infections with penicillin-resistant staphylococci acquired in hospital (all of column 5 and most of column 6 ) may be due to strains belonging to all groups, but group II provides the smallest number, and within group II only 'type 71' contains a significant number of resistant strains. 
(2) 'Type 71 ' strains, whether from impetigo or from other sources, are nearly all penicillin-resistant.

The line of demarcation between 'type 71' and other group II Staphylococcus aureus strains. The reactions of Staph. aureus with the typing phages in current use are seldom absolutely specific, and the classification of strains is based on the comparison of patterns of lysis. Although the patterns produced by strains classified as 'type 71 ' are, in fact, much more homogeneous than those produced by any other group of staphylococci thought to have common biological characteristics, a small proportion show deviations from the norm (see p. 463). It was, therefore, a matter of some importance to seek confirmation of the original definition of 'type 71 '. Two apparently independent biological characteristicsthe inhibition of corynebacteria and penicillin resistance-were common in 'type 71 ' and rare in the rest of group II; we therefore investigated the relative frequency of these characteristics among the 'normal' and two small aberrant groups of 'type 71 ' strains, and among the rest of group II.

Table 10. Proportion of 'normal' and of aberrant 'type 71' strains, and of other group II strains of Staphylococcus aureus which are (1) penicillin-resistant and (2) inhibitors of corynebacteria (DI +)

$\begin{aligned} & \text { Phage reaction } \\ & \text { No. strains tested }\end{aligned}$
$\begin{aligned} & \text { Penicillin } \\ & \text { DI reaction }\end{aligned}$

In Table 10, the distribution of these characteristics in strains from various sources is shown, and the following conclusions may be drawn:

(1) Among the 'normal 71' strains, penicillin sensitivity and absence of inhibitory power occurred independently: a penicillin-sensitive strain was as likely to be DI + as a resistant strain.

(2) 'Pure 71' strains showed no more penicillin-sensitive or DI - strains than 'normal 71' strains.

(3) However, 'weak 71 ' strains showed a greater tendency to aberration. Only 9 out of 16 were both DI + and penicillin-resistant and 5 were both DI - and penicillin-sensitive.

(4) Among other group II strains, 67/77 were DI - and penicillin-sensitive. Five were DI + and 6 penicillin-resistant, but only 1 had both these characteristics.

(5) Aberrant 'type 71' strains were not associated with any particular type of lesion. 
On the whole, these results justify the original definition of 'type 71'. They indicate that the strains in the 'pure 71 ' subdivision (those giving no minor crossreactions with other group II phages) do not differ in any detectable way from the common type. It is among the 'weak 71 ' strains (those failing to react with phage 71 at its routine test dilution) that organisms with characters intermediate between 'type 71' and the rest of group II are most commonly to be found.

Serological typing of Streptococcus pyogenes. All except 4 of the 90 strains of Str. pyogenes isolated from impetigo lesions in south-east Lancashire were tested for serological type. Unfortunately only 3 were typable by the precipitin method which, depending on the $M$ antigen, is ordinarily to be preferred because it rarely gives any cross-reactions between types. All but 7 of the remaining 83 strains could, however, be less precisely identified by the slide-agglutination method, although patterns of reactions with sera for 2 or more types were usual. Table 11 gives the agglutination patterns; the strains entered as 3/13/B 3264, for example, were agglutinated by one or more of the sera for types 3 and 13 and the provisional type B 3264 .

\section{Table 11. Serological typing of Streptococcus pyogenes}

\begin{tabular}{|c|c|c|c|c|c|c|}
\hline & & & No. of & strains fror & & \\
\hline & & & & Source & other than $\mathrm{s}$ & kin lesions \\
\hline & & & & & & \\
\hline 'Type' & $\begin{array}{c}1 \\
\text { S.E. } \\
\text { Lancs. } \\
1953-4\end{array}$ & $\begin{array}{c}2 \\
\text { Other } \\
\text { regions } \\
1953-4\end{array}$ & $\begin{array}{c}3 \\
\text { Cambridge } \\
\text { 1941-2 }\end{array}$ & $\begin{array}{c}4 \\
\text { Salford } \\
1953\end{array}$ & $\begin{array}{c}5 \\
\text { Manchester } \\
1952-4\end{array}$ & $\begin{array}{c}\text { England, } \\
\text { Wales and } \\
\text { N. Ireland } \\
\text { 1952-4 }\end{array}$ \\
\hline 3/13/B 3264 (12)* & $33 \quad 38 \%$ & $1430 \%$ & $1616 \%$ & $12 \%$ & $3 \quad 3 \%$ & $67 \quad 6 \%$ \\
\hline $5 / 11 / 12 / 27 / 44$ & $3440 \%$ & $817 \%$ & $2625 \%$ & $614 \%$ & $1314 \%$ & $11310 \%$ \\
\hline 8/25/Imp. 19 & 2 & 3 & $2625 \%$ & 6 & 3 & 28 \\
\hline Other types & 10 & 19 & 17 & 27 & 67 & 919 \\
\hline $\begin{array}{c}\text { Untypable and } \\
\text { unclassifiable }\end{array}$ & 7 & 3 & 17 & 2 & 4 & 34 \\
\hline Total & 86 & 47 & 102 & 42 & 90 & 1,161 \\
\hline
\end{tabular}

The striking feature of the results was the great predominance of strains giving two agglutination patterns-3/13/B 3264 (some also being agglutinated by the type 12 serum) and 5/11/12/27/44. These two 'types' accounted for $78 \%$ of the strains from south-east Lancashire (column 1 ) and for $47 \%$ of the impetigo strains from elsewhere (column 2). In contrast, the figures from the type distribution surveys carried out by the Public Health Laboratory Service since 1952 (Report, 1954) show that, for the country as a whole, strains from sites other than the skin included only $16 \%$ of these two types (column 6). It was, however, important to show that the predominance of the $3 / 13 / B 3264$ and 5/11/12/27/44 strains in impetigo in south-east Lancashire was not due to a predominance of these types in all infections in that region. Therefore, 42 strains isolated from nose, throat and ear swabs in the Salford laboratory were typed (Table 11, column 4), and these, 
together with the records of strains from the Manchester laboratory contributed to the P.H.L.S. surveys (column 5), form further control material. Only $16 \%$ of the Salford strains and $17 \%$ of the Manchester strains fell into the two groups dominant in impetigo-percentages that are very close to those for the country as a whole.

It may also be noted here that, of 102 strains of Str. pyogenes tested in the Cambridge investigation by $\mathrm{Dr} \mathrm{N}$. Crowley, 16 were agglutinated by sera of the $3 / 13$, etc., group, 26 by sera for types 11,12 or 27 , and 26 by sera for types 8,25 or Imp. 19 (column 3).

\section{DISCUSSION}

In 1941 Simpson expressed the opinion that ' . . the causal organism of impetigo contagiosa is an organism special to the disease'. He reached this conclusion on epidemiological grounds and drew attention to the fact that '...contacts of impetigo contagiosa do not through the infection primarily develop furuncles, cellulitis or osteomyelitis. Nor do erysipelas, cellulitis, furunculosis, carbuncle, osteomyelitis or scarlet fever ever give rise to impetigo contagiosa'. He appears to have accepted the view current at that time that the causative organism must be some sort of streptococcus. Some writers have drawn attention to the similarity between the seasonal variation in the incidence of impetigo and scarlet fever (Newman, 1935; Cruickshank, 1953), but such relationships may well be fortuitous, and a direct association between outbreaks of the diseases has not been claimed. Indeed, Simpson's opinion that impetigo 'breeds true' has never been formally controverted.

The findings that one 'type' of Staph. aureus and two 'types' of Str. pyogenes at present account for a large part of the bacterial flora of impetigo lesions, and that two of the three organisms are quite uncommon in other situations, should redirect our attention to Simpson's opinion and stimulate further investigations. Barrow (1955), who has recently examined staphylococci and streptococci from a large series of impetigo cases in Bradford, has obtained results substantially in agreement with ours. It is not possible, yet, to assess the relative importance of Staph. aureus and of Str. pyogenes in impetigo. Further studies, in which the bacteriological results can be closely related to a detailed clinical description of the cases, may help to answer this question.

The repeated demonstration over the past 25 years that single serological types of Str. pyogenes can cause a wide variety of diseases has perhaps tended to obscure the association of certain types with certain infections, although the recent observation that nephritis is almost exclusively associated with type 12 infections (Rammelkamp, Weaver \& Dingle, 1952; Wilmers, Cunliffe \& Williams, 1954) has served to re-awaken interest in this problem. The fact that a very small proportion of the haemolytic streptococci from impetigo cases are typable by the $M$ precipitin method appears to be due to the peculiar type distribution of impetigo streptococci. Strains with agglutination patterns identical with those common in impetigo lesions, but isolated from other sources, often fail to yield an active M extract; and when strains of types that usually have an $M$ antigen were found in impetigo lesions they reacted normally in the precipitin test. 
Evidence of qualitative, as well as quantitative, differences in the pathogenicity of strains of Staph. aureus has been accumulating for some years, and such differences have been correlated in a general way with susceptibility to typing phages. The production of enterotoxin almost exclusively by group III strains (Allison, 1949), and the frequency of group I strains in influenzal pneumonia in 1949 and 1951 (Williams, Rippon \& Dowsett, 1953), are examples of this. We now have suggestive evidence that 'type 71 ' contains a high proportion of strains with a special ability to invade or at least to multiply in the superficial layers of the skin.

The widespread use of penicillin cannot alone explain the present prevalence of 'type 71 ' in impetigo, since most penicillin-resistant hospital infections are due to other types of staplylococci. It is significant that in 1941, before the introduction of penicillin, strains capable of inhibiting corynebacteria were common in impetigo and rare in other situations. It would be of great interest to be able to examine a series of strains isolated from impetigo before the introduction of penicillin. Even now, penicillin-resistant strains are rarely encountered outside hospitals, and practically never belong to phage group II, except in superficial skin infections. Since penicillin has never been particularly successful in the treatment of impetigo, one wonders whether the origin of the resistance in these strains might differ in some way from that of the resistant strains that have appeared in hospitals.

\section{SUMMARY}

In an investigation of impetigo among troops, carried out in 1941, nearly half of the strains of Staphylococcus aureus isolated from the lesions had the ability to inhibit the growth of corynebacteria on solid media. A much smaller proportion of strains from other superficial lesions and from nose and throat swabs had this ability, and strains from deep suppurative lesions were uniformly negative.

Three-quarters of Staph. aureus strains isolated from schoolchildren with impetigo in Lancashire in 1953 and early 1954 were of one variety, which could be defined by its susceptibility to typing phages ('type 71 ').

Nearly $90 \%$ of 'type 71 ' staphylococci, and very few others, produced a narrow, sharp zone of inhibition of Corynebacterium diphtheriae mitis on solid media. A small number of other staphylococci, mainly non-typable or unclassifiable strains, produced a wider, hazy zone of inhibition.

The majority of the impetigo staphylococci were penicillin-resistant, and most of the resistant strains were members of 'type 71'. However, 'type 71 ' gave rise to only a small proportion of the penicillin-resistant hospital infections occurring in the same district at the same time.

Three-quarters of the Str. pyogenes strains from impetigo lesions belonged to one of two groups of closely related serological types, one of which was rarely encountered in other situations.

We wish to express our gratitude to Dr J. L. Burn, M.O.H., City of Salford, and his staff for their co-operation in this investigation, and to Dr A. V. Stocks, M.O.H., Borough of Eccles and Dr E. M. Jenkins, School Medical Officer, City of Manchester, for submitting specimens at our request. We wish to thank the many 
hospital pathologists and directors of public health laboratories who sent us cultures. We also with to acknowledge the co-operation of Dr L. C. Martin and Dr N. Crowley in the Cambridge investigation. We are grateful to Messrs G. S. Fearnehough, F.I.M.L.T., and L. Simmons, A.I.M.L.T., for technical assistance in Manchester.

\section{ADDENDUM}

Since this paper was submitted for publication, Spittlehouse (1955, Lancet, ii, 378) has reported briefly on an investigation of impetigo staphylococci isolated in Sheffield in 1954-5 in which he also observed a preponderance of strains of 'type 71 ', thus offering further confirmation of our observations.

\section{REFERENCES}

Allison, V. D. (1949). In discussion on food-poisoning. Proc. R. Soc. Med. 42, 216.

Barrow, G. I. (1955). Clinical and bacteriological aspects of impetigo contagiosa. J. Hyg., Camb., 53, 495.

Bigger, J. W. \& Hodgson, G. A. (1943). Impetigo contagiosa, its cause and treatment. Lancet, i, 544.

Burn, J. L. (1954). In Ann. Rep. M.O.H. City of Salford, 1953.

Cadness-Graves, Bessie, Williams, R., Harper, G. J. \& Miles, A. A. (1943). Slide-test for coagulase-positive staphylococci. Lancet. i, 736.

Cruickshank, R. (1953). The epidemiology of some skin infections. Brit. med. J. i, 55.

Dujardin-Beaumetz, E. (1932). Action antibiotique d'une variété de staphylocoque à l'égard des bacilles Gram-positifs et acido-résistants. C.R. Soc. Biol., Paris, 110, 1210.

Duliscoü̈r, R. (1935). Action probiotique et antibiotique des staphylocoques chez les porteurs de germes diphtériques. C.R. Soc. Biol., Paris, 118, 1277.

DuliscouËT, R. (1939). Recherches expérimentales sur une substance bactériolytique dérivée des germes antagonistes. Les applications dans la thérapeutique de la diphtérie. Arch. Méd. Pharm. Nav. 129, 410.

DuliscouËT, R. (1945). Un antagoniste microbien nouveau. La staphyline antidiphtérique. Pr. méd. 53, 653.

EPSTEIN, S. (1940). Staphylococcic impetigo contagiosa. Arch. Derm. Syph., Chicago, 42, 840.

Fisk, A. (1940). The technique of the coagulase test for staphylococci. Brit.J.exp. Path. $21,311$.

Florey, H. W., Chain, E., Heatley, N. G., Jennings, M. A., Sanders, A. G., Abraham, E. P. \& Florey, M. E. (1949). Antibiotics, 2, 493. London: Oxford University Press.

Fox, W. T. (1864). On impetigo contagiosa, or porrigo. Brit. med. J. i, 467.

Fuller, A. T. (1938). The formamide method for the extraction of polysaccharides from haemolytic streptococci. Brit. J. exp. Path. 19, 130.

GrIFFITH, F. (1934). The serological classification of Streptococcus pyogenes. J. Hyg., Camb., 34,542 .

Jennings, M. A. \& Sharp, A. E. (1947). Antibacterial activity of the staphylococcus. Nature, Lond., 159, 133.

Newman, J. L. (1935). Impetigo contagiosa, its epidemiology and control. J. Hyg., Camb., $35,150$.

Rammelkamp, C. H. Jr., Weaver, R. S. \& Dingle, J. H. (1952). Significance of the epidemiological differences between acute nephritis and acute rheumatic fever. Trans. Ass. Amer. Phycns, 65, 168.

REPORT (1954). Serotypes of Streptococcus pyogenes. Their relative prevalence in England, Wales \& Northern Ireland, 1952-53. Mon. Bull. Minist. Hlth Lab. Serv. 13, 171.

RubBo, S. D. \& Benjamin, M. (1951). Some observations on survival of pathogenic bacteria on cotton-wool swabs: development of a new type of swab. Brit. med. J. i, 983.

Shemenan, H.L. \& Fergusson, A. G. (1943). Impetigo : aetiology and treatment. Lancet, $i, 547$. Simpson, R. E. H. (1941). The impetigococcus. Lancet, i, 683.

Sneddon, I. (1953). Skin affections of the school child. Publ. Hlth, Lond., 67, 5. 
Swift, H. F., Wilson, A. T. \& Lancefield, Rebecca, C. (1943). Typing group A hemolytic streptococci by $\mathrm{M}$ precipitin reactions in capillary pipettes. J. exp. Med. 78, 127.

VÁCZI, L. \& MIHÁLYFI, I. (1954). Über die gegen Corynebakterien antagonistischen Staphyloccocus pyogenes-Stämme. Acta Microbiologica (Budapest), 1, 459.

Wilmers, Mary J., Cunliffe, A. C. \& Winliams, R. E. O. (1954). Type-12 streptococci associated with acute haemorrhagic nephritis. Lancet, ii, 17.

Williams, R. E. O. \& RipPon, JoAn E. (1952). Bacteriophage typing of Staphylococcus aureus. J. Hyg., Camb., 50, 320.

Williams, R. E. O., Rippon, Joan E. \& Dowsett, Lynette, M. (1953). Bacteriophage typing of strains of Staphylococcus aureus from various sources. Lancet, i, 510.

(MS. received for publication 15. vI. 55) 